\title{
The Rossby radius in the Arctic Ocean
}

\author{
A. J. G. Nurser and S. Bacon \\ National Oceanography Centre, Southampton, UK \\ Correspondence to: S. Bacon (s.bacon@noc.ac.uk) \\ Received: 25 September 2013 - Published in Ocean Sci. Discuss.: 22 October 2013 \\ Revised: 10 October 2014 - Accepted: 29 October 2014 - Published: 28 November 2014
}

\begin{abstract}
The first (and second) baroclinic deformation (or Rossby) radii are presented north of $\sim 60^{\circ} \mathrm{N}$, focusing on deep basins and shelf seas in the high Arctic Ocean, the Nordic seas, Baffin Bay, Hudson Bay and the Canadian Arctic Archipelago, derived from climatological ocean data. In the high Arctic Ocean, the first Rossby radius increases from $\sim 5 \mathrm{~km}$ in the Nansen Basin to $\sim 15 \mathrm{~km}$ in the central Canadian Basin. In the shelf seas and elsewhere, values are low (1-7 km), reflecting weak density stratification, shallow water, or both. Seasonality strongly impacts the Rossby radius only in shallow seas, where winter homogenization of the water column can reduce it to below $1 \mathrm{~km}$. Greater detail is seen in the output from an ice-ocean general circulation model, of higher resolution than the climatology. To assess the impact of secular variability, 10 years (2003-2012) of hydrographic stations along $150^{\circ} \mathrm{W}$ in the Beaufort Gyre are also analysed. The first-mode Rossby radius increases over this period by $\sim 20 \%$. Finally, we review the observed scales of Arctic Ocean eddies.
\end{abstract}

\section{Introduction}

The first baroclinic Rossby radius of deformation is of fundamental importance in atmosphere-ocean dynamics. It is the horizontal scale at which rotation effects become as important as buoyancy effects, or more precisely, the horizontal scale of perturbation over which the vortex stretching and relative vorticity associated with sloping isopycnals make approximately equal contributions to potential vorticity. It is the horizontal scale of geostrophic relaxation, and the "natural" scale of baroclinic boundary currents, eddies and fronts. It sets the scale of the waves that grow most rapidly as a result of baroclinic instability, and the long Rossby wave speed (Gill, 1982; Chelton et al., 1998; Saenko, 2006).
In the context of ocean models, it is important to know the field of the Rossby radius so that we know where models will describe boundary currents and the eddy field adequately and where they will not. A minimum of two grid points per eddy radius is necessary to resolve eddies adequately, and one grid point per radius to "permit" them: e.g. Smith et al. (2000), Hecht and Smith (2008). Hallberg (2013) suggests that eddy parameterizations may no longer be necessary once the ratio of the baroclinic deformation radius to a model's effective grid spacing is greater than a value of about 2, where "effective spacing" means the grid-diagonal distance. The typical best resolution in oceanic general circulation models (OGCMs) is currently $\sim 0.1^{\circ}$ (ca. $10 \mathrm{~km}$ ). In the deeper waters of the Arctic Ocean and over much of the Nordic seas, stratification is generally weak, so the Rossby radius might be expected to be significantly smaller than the $30-50 \mathrm{~km}$ characteristic of the mid-latitude oceans. OGCMs will therefore (typically) be eddy-permitting in the Arctic region at best. Over the broad Arctic Ocean shelf seas, the Rossby radius will be even smaller, and here OGCMs will not even be eddy-permitting. Chelton et al. (1998) - C98 hereafter - describe the quasi-global geographical variability of the first baroclinic Rossby radius, but their analysis does not extend north of $\sim 60^{\circ} \mathrm{N}$. This motivates the present study, which is structured as follows. In Sect. 2, we present our methods and data; Sect. 3 describes results, including uncertainties; Sect. 4 is discussion; and Sect. 5 presents some final remarks.

\section{Methods and data}

The standard method of finding the internal deformation (Rossby) radii involves solving the linearized quasigeostrophic potential vorticity equation for zero background mean flow, and is described by C98. Briefly, solutions for 
the velocity are separated into horizontal and vertical components, where the structure of the vertical velocity $\varphi(z)$ must satisfy

$N^{-2}(z) \frac{\mathrm{d}^{2} \varphi}{\mathrm{d} z^{2}}+c^{-2} \varphi=0$,

where $z$ is the vertical coordinate, and $N$ is the buoyancy frequency, defined by

$N^{-2}=-\frac{g}{\rho} \frac{\partial \rho_{\mathrm{loc}}}{\partial z}=g\left(\alpha \frac{\partial \theta}{\partial z}-\beta \frac{\partial S}{\partial z}\right)$.

Here $g$ is the acceleration due to gravity, $\rho$ is in situ density, and $\rho_{\text {loc }}$ is the potential density referenced to the depth at which $N^{2}$ is being calculated. In the term on the RHS (an approximate form), $\theta$ and $S$ are potential temperature and salinity respectively, and $\alpha$ and $\beta$ are the thermal expansion and haline contraction coefficients (Gill, 1982). The boundary conditions to be satisfied are zero vertical velocity at the surface and ocean floor:

$\varphi=0$ at $z=-H, z=0$,

where $H$ is ocean depth. Solutions are possible only for certain values of $c^{-2}$ (the eigenvalues). The corresponding $c_{i}$ (decreasing with increasing $i$ ) are then the phase speeds of the internal gravity waves, for internal modes $i=1,2, \ldots$, while the Rossby radii $R_{i}$ are

$R_{i}=c_{i} /|f|$,

where $f=2 \Omega \sin \Theta$ is the Coriolis parameter for earth rotation rate $\Omega$ and latitude $\Theta$. The $c_{i}$ may be found exactly by numerically integrating Eq. (1) to find values of $c$ that satisfy the conditions of Eq. (3). The eigenvalue problem of Eq. (1) depends only on $N^{2}$, so that solutions only require knowledge of the local vertical density gradient. Variations in $f$ have little influence on $R_{i}$ within the Arctic Ocean and Nordic seas $-\sin \left(90^{\circ}, 80^{\circ}, 70^{\circ}, 60^{\circ}\right)=(1,0.985,0.940$, 0.866 ) - but are, of course, important in reducing the deformation radius from low to high latitudes.

In the presence of sloping topography, the separation of disturbances into vertical and horizontal modes breaks down, because the vertical velocity need not be zero on the ocean floor, so the conditions of Eq. (3) no longer hold. Hence the idea of an internal-wave speed (and therefore Rossby radius) that is independent of the horizontal structure is no longer strictly appropriate. However, simple "flat-bottomed" values of the Rossby radius (which we present below) remain useful estimates of the various horizontal scales outlined in Sect. 1.

We also calculate the Rossby radius using the WKBJ/LG method, as derived by $\mathrm{C} 98$, wherein approximate, analytical solutions to Eq. (1) are sought, subject to the boundary conditions of Eq. (3). The $c_{i}$ are found by this method to be

$c_{i}=(\pi i)^{-1} \int_{-H}^{0} N \mathrm{~d} z$

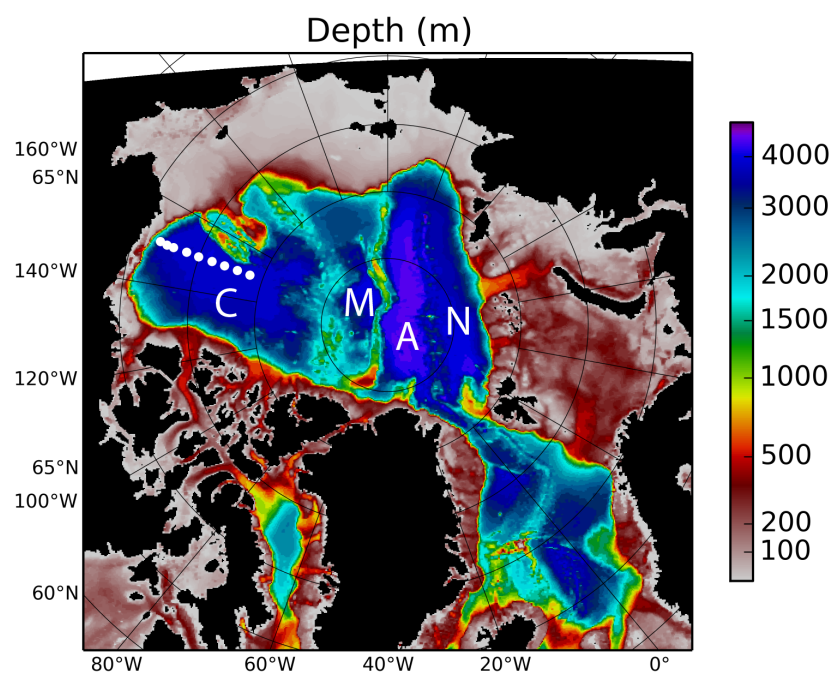

Figure 1. Bathymetry (m) of the Arctic Ocean and environs. The four major basins of the deep Arctic Ocean are labelled: Canadian (C), Makarov (M), Amundsen (A), Nansen (N). Representative station positions from the BGEP along $150^{\circ} \mathrm{W}$ are shown as white dots.

subject to the requirement that $\varphi$ should change slowly in the vertical compared with the length scale $(c / N)$. C98 found that this approximation worked surprisingly well in generating a global climatology of $R_{1}$. Equation (5) can be further simplified, assuming constant $N$ (Gill, 1982), which is useful for order-of-magnitude estimation of Rossby radii:

$c_{i}=\frac{N H}{i \pi}$.

We calculate the fields of the internal Rossby radius from the temperature and salinity fields of the Polar Science Center Hydrographic Climatology (PHC; Steele et al., 2001). PHC fields are provided on a $1^{\circ} \times 1^{\circ}$ latitude-longitude grid, with vertical resolution increasing from $10 \mathrm{~m}$ near the surface, through $100 \mathrm{~m}$ at mid-depths $(300-1500 \mathrm{~m})$, to $500 \mathrm{~m}$ below $2000 \mathrm{~m}$. We use here the annual and seasonal fields, where the seasons are defined in the PHC as the months of July, August and September (summer), and March, April and May (winter).

To assess the magnitude of interannual variability of the Rossby radius, we use hydrographic profile data from the Beaufort Gyre Exploration Project (BGEP; Proshutinsky et al., 2009). We focus on the annually repeated section (2003-2012) along $150^{\circ} \mathrm{W}$, between the north Alaskan shelf and the central Beaufort Gyre in the Canadian Basin. Station locations are included in Fig. 1.

We also calculate the fields of the internal Rossby radius from the temperature and salinity fields produced by the OCCAM global $1 / 12^{\circ}$ model (Marsh et al., 2009). In the Arctic, the horizontal resolution is $\sim 9 \mathrm{~km}$. The model has $66 \mathrm{lev}-$ els in the vertical and includes 27 levels in the upper $400 \mathrm{~m}$ 
with thickness ranging from $5.4 \mathrm{~m}$ in the uppermost layer to $48 \mathrm{~m}$ at $400 \mathrm{~m}$ and to $103 \mathrm{~m}$ at $1000 \mathrm{~m}$. In the Arctic, OCCAM was initialized with PHC. It was then run from 1985 to 2004 (Marsh et al., 2009) using surface fluxes generated from bulk formulae using model sea surface temperature and atmospheric output from the US National Centers for Climate Research, together with satellite solar forcing and precipitation. The OCCAM model bathymetry, which we use to illustrate Arctic Ocean regional bathymetry (Fig. 1), is derived from the bathymetry of Smith and Sandwell (1997), patched north of $72.0^{\circ} \mathrm{N}$ with the International Bathymetric Chart of the Arctic Ocean (IBCAO) data set (Jakobsson et al., 2000); see Aksenov et al. (2010a) for further details.

The usefulness of OCCAM in the Arctic has been demonstrated in a series of recent papers: Aksenov et al. (2010a, b, 2011) describe the Atlantic water inflows, the polar water outflows, and the representation of the Arctic Circumpolar Boundary Current in the model. We use OCCAM output for a number of reasons. The model has high horizontal and vertical resolution, and realistic coastlines, so it interpolates and (to some extent) extrapolates the climatological initialization. The model imposes dynamical consistency throughout the domain, and by choosing output a few years from the start of the run (here we inspect March and August 1992), most inconsistencies associated with spin-up are avoided. The model is spun up from rest, and Fig. 1 in Aksenov et al. (2010a) show that global mean kinetic energy stabilizes after a few years, so that the model's dynamical state is close to equilibrium, while the thermodynamic state has drifted little from the initial conditions.

\section{Results}

The annual mean first and second mode Rossby radii $\left(R_{1}\right.$, $R_{2}$ ) and the mode 1 seasonal (summer minus winter) difference as derived from PHC fields are shown in Fig. 2. Mean values for sub-regions are presented in Table 1, and the subregions are defined in Table 1 and Fig. 3. There is substantial variation in deformation radii over the Arctic. Considering $R_{1}$ first, in the deep basins of the Arctic Ocean, its annual mean values increase quasi-monotonically, with typical values ranging from $\sim 7 \mathrm{~km}$ in the Nansen Basin, through $9-10 \mathrm{~km}$ in the Amundsen Basin, $11 \mathrm{~km}$ in the Makarov Basin, to the largest values of $\sim 15 \mathrm{~km}$, found towards the centre of the Canadian Basin. This reflects the increase in stratification resulting from the progressive decrease in upper-ocean salinity from the Amundsen to the Canadian Basin (e.g. Carmack, 2000).

The deep Nordic seas are divided by the mid-basin ridge system. The Norwegian Sea contains the Atlantic-dominated inflows, where $R_{1} \sim 7 \mathrm{~km}$. The Iceland and Greenland seas contain the polar-dominated outflows, where $R_{1} \sim 3 \mathrm{~km}$. All the shallow shelf seas show very small values of $R_{1}-$ generally less than $2 \mathrm{~km}$, and in places significantly less than $1 \mathrm{~km}$.
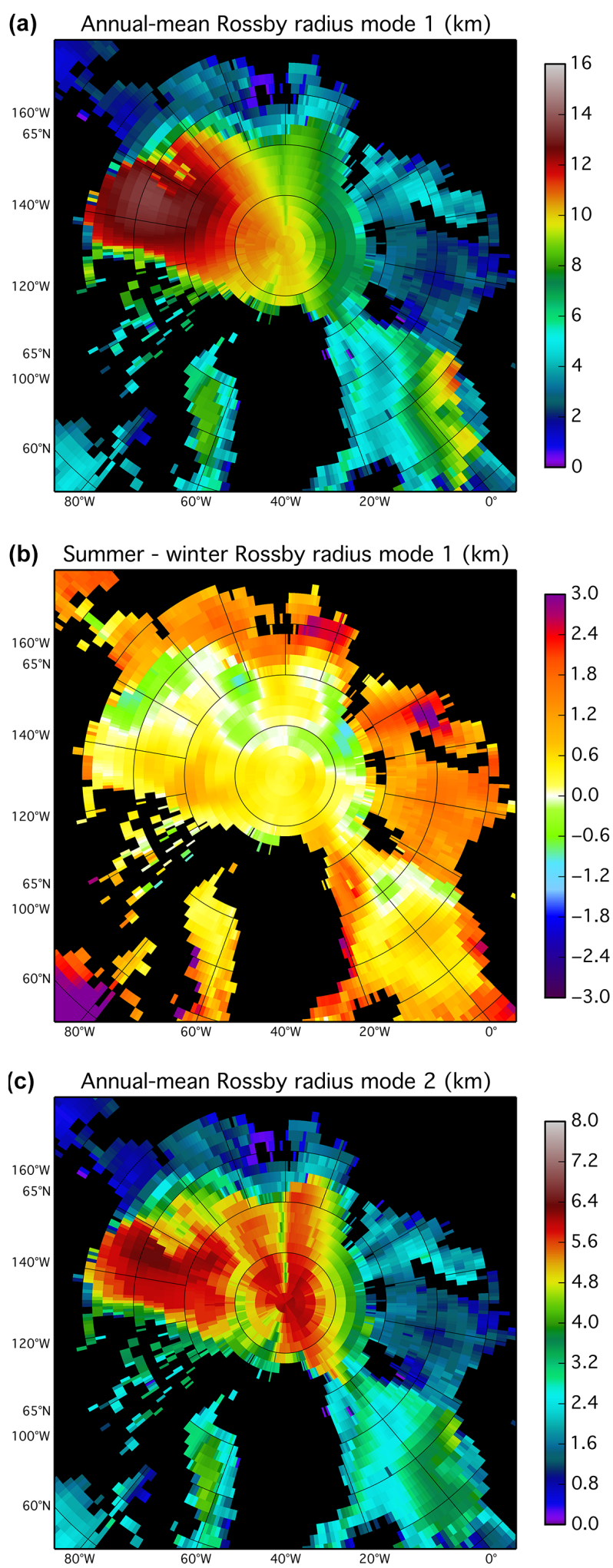

Figure 2. (a) PHC annual mean Rossby radius (km), mode 1. (b) PHC Rossby radius (km), mode 1, seasonal difference (summer minus winter). (c) PHC annual mean Rossby radius (km), mode 2. 
Table 1. Regional averages of Rossby radii mode 1 (summer, winter and annual) and mode 2 (annual). The tabulated regions are shown in Fig. 3, to which the key numbers refer. The Amerasian Basin combines the Canadian and Makarov basins; the Eurasian Basin combines the Amundsen and Nansen basins.

\begin{tabular}{|c|c|c|c|c|c|}
\hline \multirow[t]{2}{*}{ Region } & \multirow[t]{2}{*}{ Key } & \multicolumn{3}{|c|}{ Mode $1(\mathrm{~km})$} & \multirow{2}{*}{$\begin{array}{c}\text { Mode } 2(\mathrm{~km}) \\
\text { Annual }\end{array}$} \\
\hline & & Summer & Winter & Annual & \\
\hline & \multicolumn{5}{|c|}{ Deep Arctic Ocean } \\
\hline Amerasian Basin & 1 & 11.2 & 11.0 & 11.1 & 5.2 \\
\hline \multirow[t]{2}{*}{ Eurasian Basin } & 2 & 7.9 & 7.7 & 7.8 & 4.6 \\
\hline & \multicolumn{5}{|c|}{ Environs of Canadian waters } \\
\hline Canadian Archipelago & 3 & 6.3 & 5.9 & 6.1 & 2.9 \\
\hline Hudson Bay \& Foxe Basin & 4 & 4.8 & 2.7 & 3.7 & 1.9 \\
\hline \multirow[t]{2}{*}{ Baffin Bay } & 5 & 6.3 & 5.4 & 5.8 & 2.9 \\
\hline & \multicolumn{5}{|c|}{ Nordic seas } \\
\hline Greenland Sea & 6 & 5.1 & 4.4 & 4.7 & 2.6 \\
\hline Iceland Sea & 7 & 5.0 & 3.8 & 4.3 & 2.4 \\
\hline \multirow[t]{2}{*}{ Norwegian Sea } & 8 & 7.2 & 6.5 & 6.9 & 3.0 \\
\hline & \multicolumn{5}{|c|}{ Eurasian Shelf seas } \\
\hline Barents Sea & 9 & 3.3 & 1.9 & 2.5 & 1.3 \\
\hline White Sea & 10 & 3.5 & 2.4 & 2.7 & 1.4 \\
\hline Kara Sea & 11 & 4.6 & 3.0 & 3.8 & 1.9 \\
\hline East Siberian Shelf seas & 12 & 3.7 & 2.5 & 3.1 & 1.4 \\
\hline
\end{tabular}

The seasonal variation is most pronounced in the shallow shelf seas, where riverine freshwater inputs and sea ice melt cause high summer stratification, and wintertime convective homogenization of the water column causes low stratification.

Amplitudes of $R_{2}$ are roughly half of those of $R_{1}$, because the wave speed solutions scale with mode number (see Eq. 5 below) and the contrast between shallow shelf seas and deep ocean is similar. However, the mode 2 structure is subtly different to that of mode 1 , in that the trans-polar increasing tendency is largely absent.

There are of course substantial uncertainties associated with these estimates. The first contribution to the uncertainty is secular (interannual to decadal) variability, and the most notable secular variability in Arctic Ocean properties is the increase in stored freshwater in the Beaufort Gyre within the Canadian Basin (Rabe et al., 2011; Morison et al., 2012), attributed to gyre spin-up (Giles et al., 2012). We calculate $R_{1}$ along the $\mathrm{BGEP} 150^{\circ} \mathrm{W}$ section for each of the 10 years 2003-2012, mainly between 72 and $79^{\circ} \mathrm{N}$ (see dots in Fig. 1). The section passes through the centre of the gyre and also through the surface salinity minimum, and therefore the stratification maximum (Fig. 4). As freshwater storage increases, so too does $R_{1}$ across the whole section, by $\sim 3 \mathrm{~km}$ overall, or $\sim 2 \%$ per year. Interestingly, there is an upward drift in $R_{1}$ between 2003 and 2007, then a jump of $>1 \mathrm{~km}$ from 2007 to 2008, after which values are relatively stable. The jump coincides with the period of unusually low sea ice

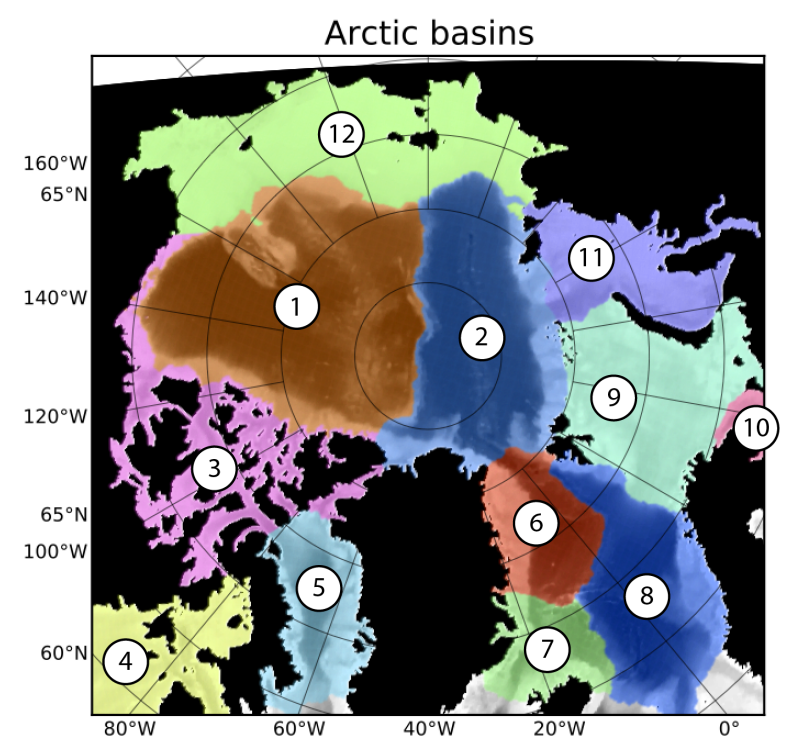

Figure 3. Division of Arctic Ocean and adjacent regions for average Rossby radius calculations; see Table 1 for identification of subregions by key number.

extent of September 2007 (Stroeve et al., 2008). PHC results lie generally within the lower, earlier range of BGEP values, but with evidence of smoothing, on which we comment below. 


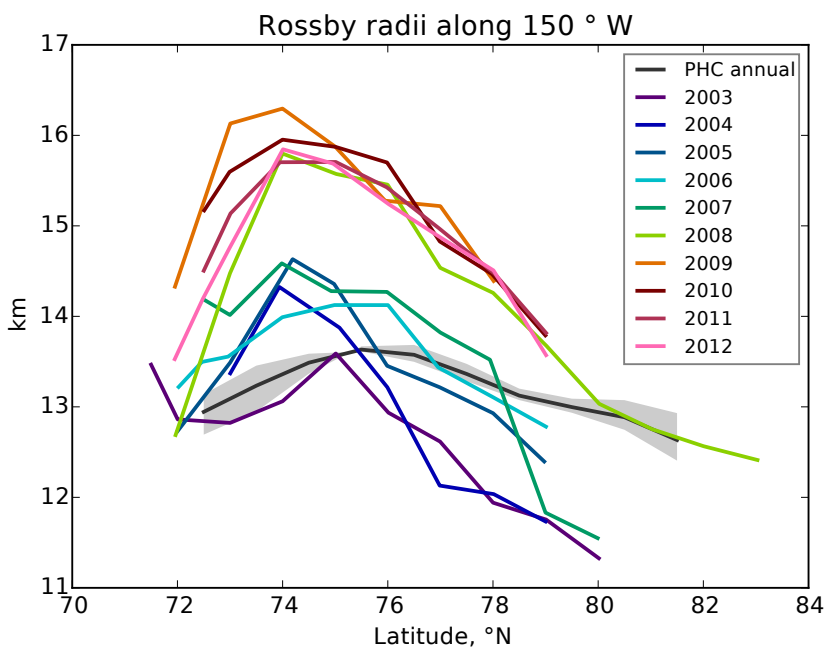

Figure 4. Rossby radius mode $1(\mathrm{~km})$ along BGEP $150^{\circ} \mathrm{W}$ hydrographic section for 2003-2012; years are identified by colour in the key. PHC values along $150^{\circ} \mathrm{W}$ are shown in black, with grey shading showing the seasonal range.

Considering uncertainties in the vertical, there is no contribution from the calculation of $N^{2}$, which is exact, through use of locally referenced potential density for both observations and model. However, a possible contribution arises from the limited vertical resolution of the PHC data. This is inspected by comparison of the Rossby radii derived from full-resolution (1 dbar) BGEP profiles with results obtained by decimation down to PHC resolution. Figure 5 shows the resulting differences (decimated minus full), for which the mean difference is $-0.05 \pm 0.07 \mathrm{~km}(1 \mathrm{SD})$, or $\sim 0.5 \%$. The bias is a consequence of the tendency of decimation to reduce the density gradient.

A "horizontal" contribution to uncertainty results from the smoothing due to the gridding process used in generating the PHC climatology. At any depth that is crossed by a density front which is included within the search radius, horizontal averaging will increase the density on the "deep" side and decrease the density on the "shallow" side (referring to isopycnal depths), with consequent impacts on $\partial \rho / \partial z$. C98 were able to form a regional (North Atlantic) assessment of the significance of horizontal smoothing by comparison of their results derived from their global horizontally averaged database with those from a parallel, isopycnally averaged product. C98 found a quasi-random uncertainty of $5 \%$ (1 SD), plus a systematic and larger contribution from averaging across the Gulf Stream and its extension, which they illustrated by overlaying dynamic topography on the geographical distribution of high positive and negative differences between climatological values of the Rossby radius. Plainly, there is nothing in the Arctic Ocean or Nordic seas of comparable strength. In their Fig. S13, Morison et al. (2012) show Arctic dynamic ocean topography (DOT; akin to dynamic height), from which it is seen that large-scale (pan-

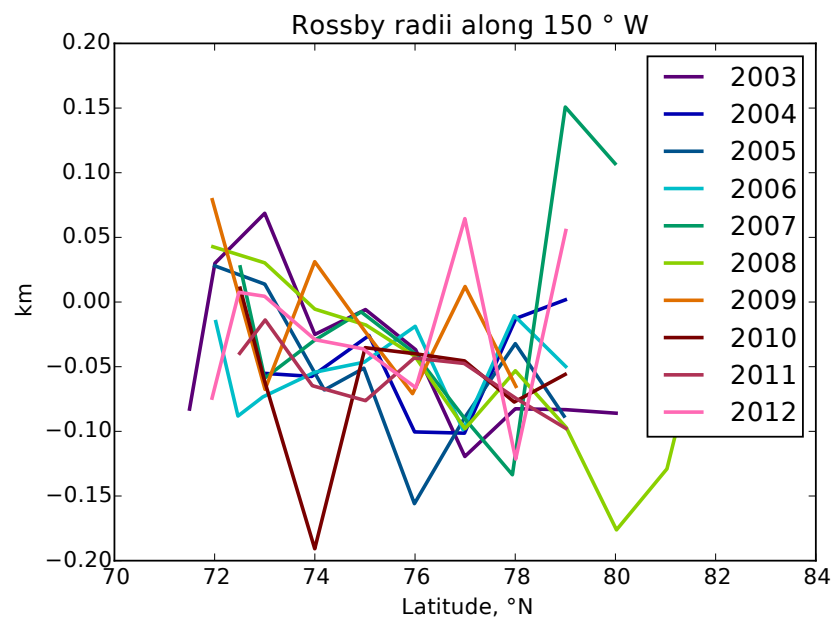

Figure 5. Difference between BGEP Rossby radii, decimated minus full resolution.

Arctic) horizontal gradients of DOT are of order $10^{-7}$, two orders of magnitude smaller than Gulf Stream values (e.g. Kelly and Gille, 1990). Near and downstream of Fram Strait, large horizontal dynamic height gradients, of order $10^{-6}$, exist across the East Greenland Current (EGC; Manley et al., 1992). Since the PHC search radius depends on the correlation length scale, and is set to $500 \mathrm{~km}$ in the Arctic Ocean and $100 \mathrm{~km}$ in the Nordic seas, some impact of horizontal averaging may be seen locally: for example, in the EGC, and also likely across the Beaufort Gyre (Fig. 4).

The net uncertainty in our PHC-derived estimates of the annual mean Rossby radius depends, therefore, on the major terms, which are (i) secular variability, (ii) seasonal variability, and (iii) the quasi-random component resulting from horizontal averaging. From the BGEP case, we estimate (i) as $10 \%$; from Fig. 2a and b, we estimate (ii) as $10 \%$, and from $\mathrm{C} 98$, we estimate (iii) as $5 \%$, for a root-sum-square total of $15 \%$.

Finally, PHC is relatively low resolution, at $1^{\circ} \times 1^{\circ}$, so we inspect output from the OCCAM model: fields of $R_{1}$ for March and August 1992 are shown in Fig. 6. Using the same regions as defined in Table 1 and Fig. 3, we find that in no region in OCCAM is $R_{1}$ more than $1.5 \mathrm{~km}$ different from PHC, with the exception of the Canadian Arctic Archipelago, where OCCAM results are approximately half those of PHC. This is not a flaw in the model but rather a consequence of the model's much higher resolution than PHC. The model is able to capture the narrow channels - with their low values of $R_{1}$ - which are absent from PHC. The major difference between model and PHC, given their quantitative similarity, lies in the detail visible in the model values: the imprint of bathymetry on $R_{1}$ stands out, particularly on the Siberian shelves, but also over the deep ocean ridges. 

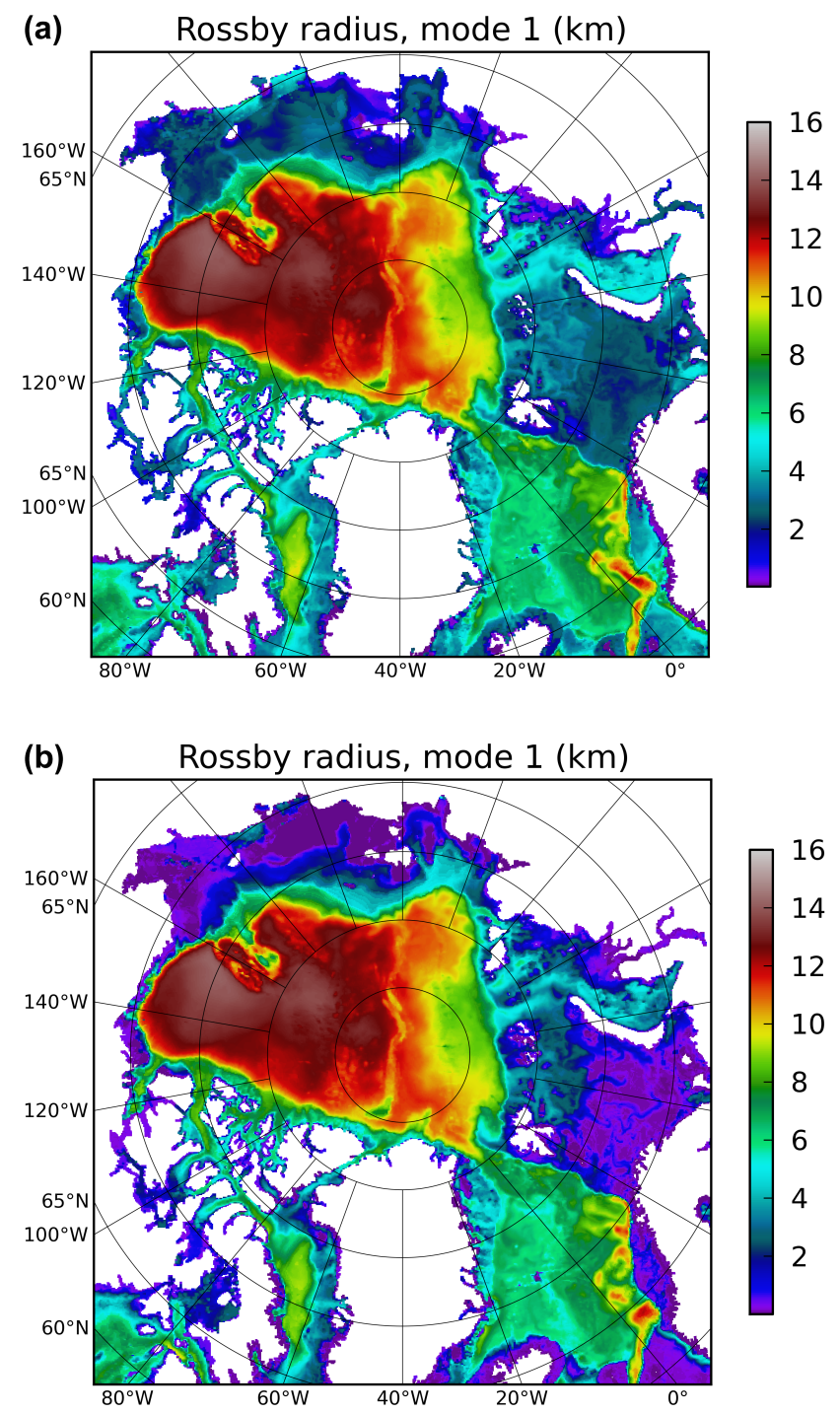

Figure 6. (a) OCCAM Rossby radius mode $1(\mathrm{~km})$ for August 1992. (b) OCCAM Rossby radius mode $1(\mathrm{~km})$ for March 1992.

\section{Discussion}

\subsection{Rossby radius and stratification}

The wide range of values of Rossby radii throughout the Arctic Ocean are a result of the interplay between density stratification and water depth, with the former largely (but not exclusively) controlled by upper-ocean salinity variability. We illustrate this as follows.

We consider three cases to illustrate high, medium and low values of $R_{1}$. We approximate Eqs. (2) and (6) by setting $g=$ $10 \mathrm{~m} \mathrm{~s}^{-2}, f=1.4 \times 10^{-4} \mathrm{~s}^{-1}, \beta=8 \times 10^{-4} \mathrm{~kg} \mathrm{~m}^{-3} \mathrm{psu}^{-1}$. The impact of temperature on density is neglected, since stratification in and around the Arctic is dominated by salinity (Carmack, 2007). For each case, we choose representative values of salinity and of scale depth, to estimate $\mathrm{d} \rho / \mathrm{d} z$.
High values of $R_{1}$ - of order $10 \mathrm{~km}$ - are found in the deep basins of the Arctic Ocean. A typical upper-ocean salinity of 32, a deep salinity of 34.8 (e.g. Carmack, 2000) and a scale depth of $1000 \mathrm{~m}$ result in $\mathrm{d} \rho / \mathrm{d} z \sim 2 \times 10^{-3} \mathrm{~kg} \mathrm{~m}^{-4}, N \sim 5 \times$ $10^{-3} \mathrm{~s}^{-1}$, and $R_{1} \sim 11 \mathrm{~km}$. Equation (5) helps to understand the choice of scale depth: the density stratification is very weak below $\sim 1000 \mathrm{~m}$, and the vertical integral of $N$ is thus dominated by the stratification above $1000 \mathrm{~m}$.

Medium values of $R_{1}$ - of order $5 \mathrm{~km}$ - are seen in the central Greenland Sea (Karstensen et al., 2005). With a surfaceto-bottom (potential) density difference of $\sim 0.1 \mathrm{~kg} \mathrm{~m}^{-3}$ and a scale depth of $3000 \mathrm{~m}$, we find $\mathrm{d} \rho / \mathrm{d} z \sim 3 \times 10^{-5} \mathrm{~kg} \mathrm{~m}^{-4}$, $N \sim 0.6 \times 10^{-3} \mathrm{~s}^{-1}$ and $R_{1} \sim 4 \mathrm{~km}$. This very low value in a deep ocean region is the result of the weak stratification that pertains throughout the water column. Several publications have described "sub-mesoscale convective vortices" found in the Greenland Sea (e.g. Gascard et al., 2002; Wadhams et al., 2002; Budeus et al., 2004), and these features have radii ca. $5 \mathrm{~km}$. It appears that these are not, in fact sub-mesoscale but mesoscale. It so happens that the mesoscale in this basin is very small.

Low values of $R_{1}$, of order $1 \mathrm{~km}$, are illustrated by considering the East Siberian Sea (Münchow et al., 1999). The scale depth is set to $50 \mathrm{~m}$ and the surface-to-bottom salinity difference to 2 , resulting in $\mathrm{d} \rho / \mathrm{d} z \sim 3 \times 10^{-2} \mathrm{~kg} \mathrm{~m}^{-4}$, $N \sim 2 \times 10^{-2} \mathrm{~s}^{-1}$ and $R_{1} \sim 2 \mathrm{~km}$. While the density gradient (and therefore $N$ ) is high, the small resulting value of $R_{1}$ is due to the small value of "full ocean depth" - around $50 \mathrm{~m}$. With homogenization of the water column (directly or indirectly) through winter heat loss, the vertical density gradient can assume very small values (significantly less than $1 \mathrm{~km}$ ), which presents a challenge to observations and models alike, given the importance of the shelf seas to Arctic freshwater fluxes and water mass structure, and thereby to local and nonlocal climate.

We assess the usefulness of the WKBJ/LG approximate solutions by plotting the difference field (exact solution minus approximation) for annual mean values of $R_{1}$ in Fig. 7 . It is seen that the WKBJ/LG method is in error typically, and over most of the region, by $\pm 1-2 \mathrm{~km}$. This represents an uncertainty of $\sim 20 \%$ over the deep basins of the Arctic Ocean, but is a larger relative uncertainty where $R_{1}$ is small - in the Greenland Sea and the shallow shelf seas. Noting that $c$ in the Arctic is nearly everywhere ca. $1 \mathrm{~m} \mathrm{~s}^{-1}$ (to within a factor 2; not shown), and using the above estimates of $N$, the vertical length scale $c / N$ is $2000 \mathrm{~m}$ in the Greenland Sea and $50 \mathrm{~m}$ in the shelf seas. In both cases, this is comparable to the water depth, so the WKBJ/LG scale assumption is not well satisfied.

There is nothing in the published literature with which to compare our results. However, Saenko (2006) describes Rossby radii calculated from an ensemble of coarse $\left(\sim 1^{\circ}\right.$ by $1^{\circ}$ ) resolution climate models up to $85^{\circ} \mathrm{N}$ using the $\mathrm{WKBJ} / \mathrm{LG}$ approximation, presented as zonal means. This is a highly unsatisfactory metric in high northern latitudes be- 


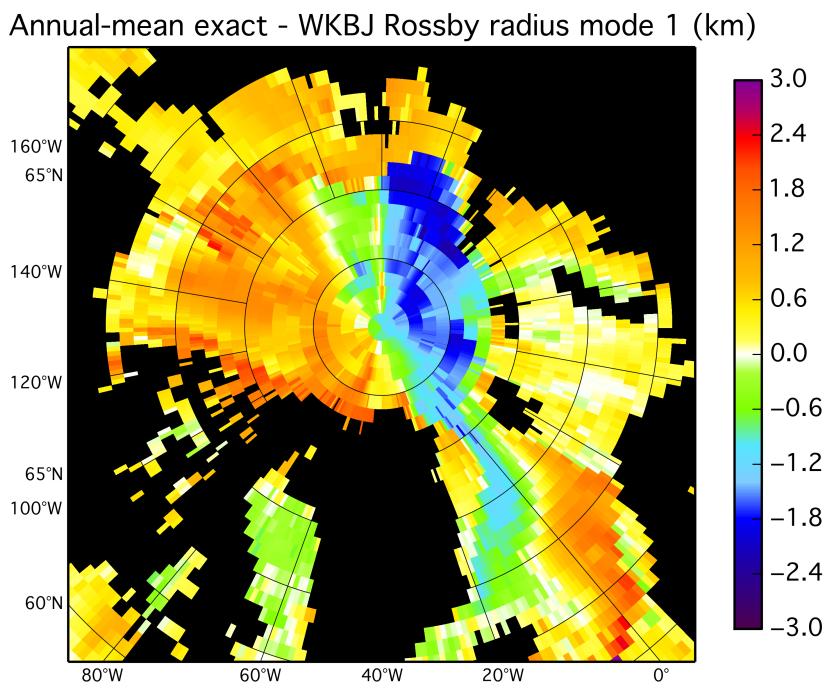

Figure 7. Difference between exact solution and WKBJ/LG approximate solution (exact minus WKB) for mode 1 Rossby radius $(\mathrm{km})$, annual mean.

cause it conflates extensive shallow shelf seas and deep ocean basins. Nevertheless, we parallel this style of presentation in Fig. 8, which shows annual, summer and winter zonal means of $R_{1}$ and $R_{2}$. Seasonality has little impact by this metric. Minimum values occur around $65-70^{\circ} \mathrm{N}$; this latitude band mainly comprises the southern Nordic seas and Davis Strait, with some elements of shelf seas. Maxima are found near the Pole $\left(85-90^{\circ} \mathrm{N}\right)$, and these waters are all of the deep Arctic Ocean. The results of Saenko (2006) bear some similarities to this. Models with the smallest mean Rossby radii are in agreement with ours, but several others show substantial latitudinally dependent overestimates. Nevertheless, it is encouraging that some models appear to be capable of producing sensible density stratification (in the zonal mean).

\subsection{Observed eddies}

There have in the past been several high-resolution surveys of Arctic Ocean eddies, reported in Newton et al. (1974), Hunkins (1974), Manley and Hunkins (1985), D’Asaro (1988), Padman et al. (1990), Muench et al. (2000), Pickart et al. (2005), Timmermans et al. (2008), Nishino et al. (2011) and Kawaguchi et al. (2012), and stemming (variously) from field programmes such as the Arctic Ice Dynamics Joint Experiment (AIDJEX) in the 1970s, the Arctic Internal Wave Experiment (AIWEX) in 1985, Scientific Ice Expedition (SCICEX) measurements from the 1990s, the Western Arctic Shelf-Basin Interaction (SBI) programme of 2005, icetethered profilers (ITPs), and an expedition on the R/V Mirai in 2010. Curiously, all these papers report on eddies observed in the Canada Basin. It is not clear whether the Canada Basin is "infested" with eddies or whether there is simply a paucity of eddy-resolving measurements in the other basins, caused

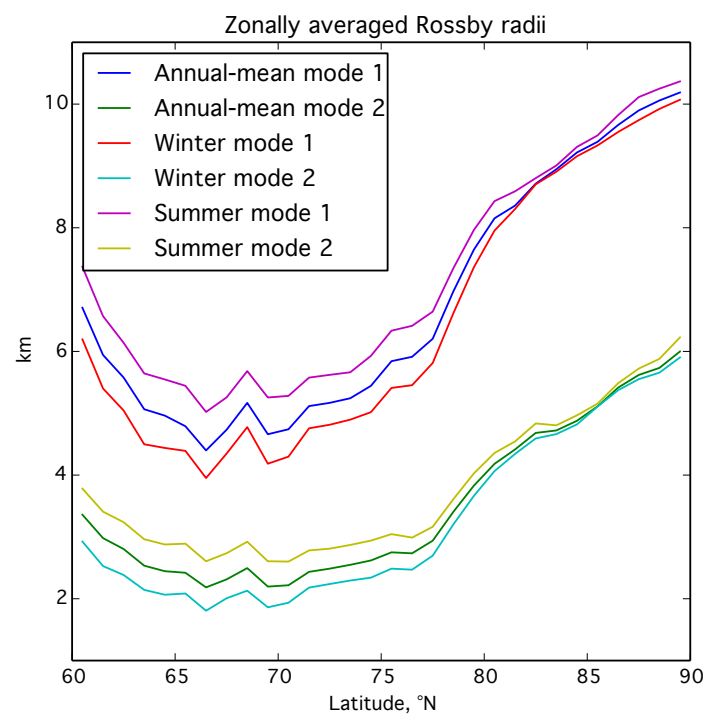

Figure 8. Zonal means of PHC Rossby radii modes 1 and 2.

by the difficulty of making such measurements given the ice cover.

Still, these cited observations are all more or less consistent in how they describe the observations. The eddy has a core where rotation is (close to) solid body, and the outer edge of the core defines the radius of maximum velocity. Further outwards from the edge of the core is a region which is still rotating but where the velocity progressively reduces (the "penumbra"; Hoskins et al., 1985), out to a maximum radius of influence. Typical core radii are $\sim 7 \mathrm{~km}$, and the typical maximum radius of influence is $\sim 15 \mathrm{~km}$. The eddy described by Kawaguchi et al. (2012) was (apparently) an unusually large one, doubling these values. An empirical quantification of this description is given by Timmermans et al. (2008).

Hoskins et al. (1985) suggest an approach (the pursuit of which is beyond the scope of the present study) whereby an explanation of these observations may be developed. At its point of generation, an eddy is in solid-body rotation. If, for example, the generation mechanism is baroclinic instability, the Rossby radius would then describe the solid-body rotation radius because (as noted in Sect. 1) it would characterize the scale of the waves that grow most rapidly as a result of baroclinic instability. Subsequently, the closedcontour potential vorticity anomaly induces flow in the surrounding volume (the penumbra). By inference, therefore, most of the observed Canadian Basin eddies should be of Mode 2, since the local value of $R_{2}$ is $\sim 6 \mathrm{~km}$ (Fig. 2c), similar to the solid-body core radii, with the exception of the large eddy (Kawaguchi et al., 2012) whose core radius is similar to the local value of $R_{1}$. As a further complication, Chelton et al. (2011) note that eddies may be 2 or 3 times larger than the Rossby radius. It is not straightforward to associate calculated Rossby radii with observations of eddies. 


\section{Final remarks}

Timmermans et al. (2008) demonstrate the feasibility of making quasi-Lagrangian observations of Arctic Ocean eddies with ice-tethered profilers, but Eulerian measurements present a challenge. The only sustained Arctic Ocean measurement programme to resolve successfully the local Rossby radius is located north of Alaska (Nikopoulos et al., 2009) with a typical moored instrument spacing of $\sim 5 \mathrm{~km}$. Furthermore, the logistical and operational constraints of trans-polar hydrographic sections conducted on research icebreakers mean that they cannot get close to resolving the Rossby radius (e.g. Carmack et al., 1997).

The main aim of this paper was to present fields of the Rossby radii in the Arctic Ocean and adjacent seas. Lacking a quantitative appreciation of Rossby radii, it is possible for features to be "missed" by measurement programmes. For example, the Shelf Break Branch of the Arctic Circumpolar Boundary Current has only recently been described (Aksenov et al., 2011). This is a shallow feature transporting halocline waters that circuits most of the Arctic Ocean. Over the shelf break the Rossby radius is typically $\sim 7 \mathrm{~km}$, so this current is sufficiently narrow that it had slipped almost unnoticed between more widely spaced standard measurement locations. The model study inspired reanalysis of past measurements, and deliberate targeting of new measurements. Advances in understanding of Arctic Ocean circulation and dynamics will likely be found from measurements and models in combination.

Acknowledgements. This study was funded by the UK Natural Environment Research Council, and is a contribution to to the UK TEA-COSI project. The PHC data were downloaded from http://www.psc.apl.washington.edu/Climatology.html, in version 3.0. BGEP data were downloaded from the project website, http://www.whoi.edu/beaufortgyre/. The authors are grateful to the editor and the reviewers for their patience, and to Takamasa Tsubouchi for help with data wrangling. Calculations were performed and plotted with the SciPy and matplotlib open source python packages (http://www.scipy.org; http://www.matplotlib.org).

Edited by: M. Hecht

\section{References}

Aksenov, Y., Bacon, S., Coward, A. C., and Nurser, A. J. G.: The North Atlantic Inflow into the Nordic Seas and Arctic Ocean: a high-resolution model study, J. Marine Sys., 79, 1-22, 2010a.

Aksenov, Y., Bacon, S., Coward, A. C., and Holliday, N. P.: Polar outflow from the Arctic Ocean: a high-resolution model study, J. Marine Sys., 83, 14-37, doi:10.1016/j.jmarsys.2010.06.007, 2010b.

Aksenov, Y., Ivanov, V. V., Nurser, A. J. G., Bacon, S., Polyakov, I. V., Coward, A. C., Naveira Garabato, A. C., and Beszczynska-
Moeller, A.: The Arctic Circumpolar Boundary Current, J. Geophys. Res., 116, C09017, doi:10.1029/2010JC006637, 2011.

Budeus, G., Cisewski, B., Ronski, S., Dietrich, D., and Weitere, M.: Structure and effects of a long lived vortex in the Greenland Sea, Geophys. Res. Lett., 31, L05304, doi:10.1029/2003GL017983, 2004.

Carmack, E. C.: The freshwater budget of the Arctic ocean: sources, storage and sinks, edited by: Lewis, E. L., NATO Adv. Res. Ser., 91-126, 2000.

Carmack, E. C.: The alpha/beta ocean distinction: a perspective on freshwater fluxes, convection, nutrients and productivity in highlatitude seas, Deep-Sea Res. II, 54, 2578-2598, 2007.

Carmack, E. C., Aagaard, K., Swift, J. H., Macdonald, R. W., McLaughlin, F. A., Jones, E. P., Perkin, R. G., Smith, J. N., Ellis, K. M., and Killius, L. R.: Changes in temperature and tracer distributions within the Arctic Ocean: results from the 1994 Arctic Ocean section, Deep-Sea Res. II, 44, 1487-1502, 1997.

Chelton, D. B., de Szoeke, R. A., Schlax, M. G., El Naggar, K., and Siwertz, N.: Geographical variability of the first baroclinic Rossby radius of deformation, J. Phys. Oceanogr., 28, 433-459, 1998.

Chelton, D. B., Schlax, M. G., and Samelson, R. M.: Global observations of nonlinear mesoscle eddies, Prog. Oceanogr., 91, 167-216, 2011.

D'Asaro, E. A.: Observations of small eddies in the Beaufort Sea, J. Geophys. Res., 93, 6669-6684, 1988.

Gascard, J.-C., Watson, A. J., Messias, M.-J., Olsson, K. A., Johannessen, J., and Simonsen, K.: Long-lived vortices as a mode of deep ventilation in the Greenland Sea, Nature, 416, 525-527, 2002.

Giles, K. A., Laxon, S. W., Ridout, A. L., Wingham, D. J., and Bacon, S.: Western Arctic Ocean freshwater storage increased by wind-driven spin-up of the Beaufort Gyre, Nat. Geosci., 5, 194-197, 2012.

Gill, A. E.: Atmosphere-Ocean Dynamics, Academic Press, 662 pp., 1982.

Hallberg, R.: Using a resolution function to regulate parameterizations of oceanic mesoscale eddy effects, Ocean Model., 72, 92-103, 2013.

Hecht, M. W. and Smith, R. D.: Toward a physical understanding of the North Atlantic: a review of model studies in an eddying regime, in: Ocean Modeling in an Eddying Regime, edited by: Hecht, M. W. and Hasumi, H., Geophys. Monog. Series, 177, 231-239, 2008.

Hoskins, B. J., McIntyre, M. E., and Robertson, A. W.: On the use and significance of isentropic potential vorticity maps, Q. J. Roy. Meteor. Soc., 111, 877-946, 1985.

Hunkins, K. L.: Subsurface eddies in the Arctic Ocean, Deep-Sea Res., 21, 1017-1033, 1974.

Jakobsson, M., Cherkis, N., Woodward, J., Macnab, R., and Coakley, B.: New grid of Arctic bathymetry aids scientists and mapmakers, Eos Trans. AGU, 81, 89-96, 2000.

Karstensen, J., Schlosser, P., Wallace, D. W. R., Bullister, J. L., and Blindheim, J.: Water mass transformation in the Greenland Sea during the 1990s, J. Geophys. Res., 110, C07022, doi:10.1029/2004JC002510, 2005.

Kawaguchi, Y., Itoh, M., and Nishino, S.: Detailed survey of a large baroclinic eddy with extremely high temperatures in the western Canada Basin, Deep-Sea Res. I, 66, 90-102, 2012. 
Kelly, K. A. and Gille, S. T.: Gulf Stream surface transport and statistics at $69^{\circ} \mathrm{W}$ from the Geosat altimeter, J. Geophys. Res., 95, 3149-3161, 1990.

Manley, T. O. and Hunkins, K.: Mesoscale eddies of the Arctic Ocean, J. Geophys. Res., 90, 4911-4930, 1985.

Manley, T. O., Bourke, R. H., and Hunkins, K. L.: Near-surface circulation over the Yermak Plateau in northern Fram Strait, J. Marine Systems, 3, 107-125, 1992.

Marsh, R., de Cuevas, B. A., Coward, A. C., Jacquin, J., J. Hirschi, J.-M., Aksenov, Y., Nurser, A. J. G., and Josey, S. A.: Recent changes in the North Atlantic circulation simulated with eddypermitting and eddy-resolving ocean models, Ocean Model., 28, 226-239, 2009.

Morison, J., Kwok, R., Peralta-Ferriz, C., Alkire, M., Rigor, I., Andersen, R., and Steele, M.: Changing Arctic Ocean freshwater pathways, Nature, 481, 66-70, 2012.

Muench, R. D., Gunn, J. T., Whitledge, T. E., Schlosser, P., and Smethie Jr., W.: An Arctic cold core eddy, J. Geophys. Res., 105, 23997-24006, 2000.

Münchow, A., Weingartner, T. J., and Cooper, L. W.: The summer hydrography and surface circulation of the East Siberian Shelf Sea, J. Phys. Oceanogr., 29, 2167-2182, 1999.

Newton, J. L., Aagaard, K., and Coachman, L. K.: Baroclinic eddies in the Arctic Ocean, Deep-Sea Res., 21, 707-719, 1974.

Nikopoulos, A., Pickart, R. S., Fratantoni, P. S., Shimada, K., Torres, D. J., and Jones, E. P.: The western Arctic boundary current at $152^{\circ} \mathrm{W}$ : structure, variability and transport, Deep-Sea Res. II, 56, 1164-1181, doi:10.1016/j.dsr2.2008.10.014, 2009.

Nishino, S., Itoh, M., Kawaguchi, Y., Kikuchi, T., and Aoyama, M.: Impact of an unusually large warm-core eddy on distributions of nutrients and phytoplankton in the southwestern Canada Basin during late summer/early fall 2010, Geophys. Res. Lett., 38, L16602, doi:10.1029/2011GL047885, 2011.

Padman, L., Levine, M., Dillon, T., Morison, J., and Pinkel, R.: Hydrography and microstructure of an Arctic cyclonic eddy, J. Geophys. Res., 95, 9411-9420, 1990.

Pickart, R. S., Weingartner, T. J., Pratt, L. J., Zimmermann, S., and Torres, D. J.: Flow of winter-transformed Pacific water into the western Arctic, Deep-Sea Res. II, 52, 3175-3198, 2005.
Proshutinsky, A., Krishfield, R., Timmermans, M.-L., Toole, J., Carmack, E., McLaughlin, F., Williams, W. J., Zimmermann, S., Itoh, M., and Shimada, K.: Beaufort Gyre freshwater reservoir: state and variability from observations, J. Geophys. Res., 114, C00A10, doi:10.1029/2008JC005104, 2009.

Rabe, B., Karcher, M., Schauer, U., Toole, J. M., Krishfield, R. A., Pisarev, S., Kauker, F., Gerdes, R., and Kikuchi, T.: An assessment of Arctic Ocean freshwater content changes from the 1990s to the 2006-2008 period, Deep-Sea Res. I, 58, 173-185, 2011.

Saenko, O. A.: Influence of global warming on baroclinic Rossby radius in the ocean: a model intercomparison, J. Climate, 19, 1354-1360, 2006.

Smith, R. D., Maltrud, M. E., Bryan, F. O., and Hecht, M. W.: Numerical simulation of the North Atlantic Ocean at $1 / 10^{\circ}$, J. Phys. Oceanogr., 30, 1532-1561, 2000.

Smith, W. H. F. and Sandwell, D. T.: Global seafloor topography from satellite altimetry and ship depth soundings, Science, 277, 1957-1962, 1997.

Steele, M., Morley, R., and Ermold, W.: PHC: A global ocean hydrography with a high quality Arctic Ocean, J. Climate, 14, 2079-2087, 2001.

Stroeve, J., Serreze, M., Drobot, S., Gearheard, S., Holland, M., Maslanik, J., Meier, W., and Scambos, T.: Arctic sea ice extent plummets in 2007, Eos, 89, 13-20, 2008.

Timmermans, M.-L., Toole, J., Proshutinsky, A., Krishfield, R., and Plueddemann, A.: Eddies in the Canada Basin, Arctic Ocean, observed from Ice-Tethered Profilers, J. Phys. Oceanogr., 38, 133-145, 2008.

Wadhams, P., Holfort, J., Hansen, E., and Wilkinson, J. P.: A deep convective chimney in the winter Greenland Sea, Geophys. Res. Lett., 29, 1434, doi:10.1029/2001GL014306, 2002. 